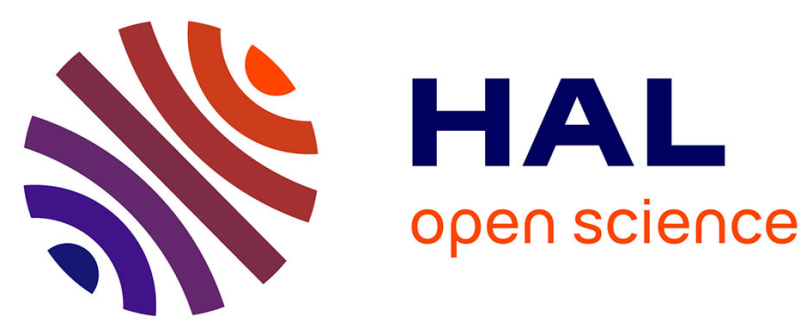

\title{
Spray-Drying Polymer Encapsulation of CsPbBr 3 Perovskite Nanocrystals with Enhanced Photostability for LED Downconverters
}

Félix Boussoufi, Marc Pousthomis, Alexis Kuntzmann, Michele D’amico, Gilles Patriarche, Benoit Dubertret

\section{To cite this version:}

Félix Boussoufi, Marc Pousthomis, Alexis Kuntzmann, Michele D'amico, Gilles Patriarche, et al.. Spray-Drying Polymer Encapsulation of CsPbBr 3 Perovskite Nanocrystals with Enhanced Photostability for LED Downconverters. ACS Applied Nano Materials, 2021, 4 (7), pp.7502-7512. 10.1021/acsanm.1c01552 . hal-03349557

\section{HAL Id: hal-03349557 https://hal.science/hal-03349557}

Submitted on 20 Sep 2021

HAL is a multi-disciplinary open access archive for the deposit and dissemination of scientific research documents, whether they are published or not. The documents may come from teaching and research institutions in France or abroad, or from public or private research centers.
L'archive ouverte pluridisciplinaire HAL, est destinée au dépôt et à la diffusion de documents scientifiques de niveau recherche, publiés ou non, émanant des établissements d'enseignement et de recherche français ou étrangers, des laboratoires publics ou privés. 


\title{
Spray-Drying Polymer Encapsulation of $\mathrm{CsPbBr}_{3}$ Perovskite Nanocrystals with Enhanced Photo-Stability for LED DownConverters
}

\author{
Félix Boussoufi, $\dagger+$ Marc Pousthomis, $\$$ Alexis Kuntzmann, $\uparrow$ Michele D’Amico, $\uparrow$ Gilles Patriarche,$\dagger$ \\ and Benoit Dubertret:
}

$\dagger$ Université Paris-Saclay, CNRS, Centre de Nanosciences et Nanotechnologies, 91120, Palaiseau, France

$\ddagger$ Nexdot, 102 Av. Gaston Roussel, 93230, Romainville, France

KEYWORDS: Cs $\mathrm{PbBr}_{3}$ perovskite nanocrystals, spray-drying, encapsulation, polymer, composite, LED down-converter,
photo-stability

\begin{abstract}
Lead halide perovskite nanocrystals (LHP NCs) exhibit remarkable optical and optoelectronical properties but greatly suffer from poor stability in standard ambient and in-use conditions. These stability issues hinder their utilization in many technological applications and in their integration within industrial processes. Herein, we report a polymeric nano-encapsulation method of these NCs based on a spray-drying process, with the aim of using them as light down-converting materials in LED devices. $\mathrm{CsPbBr}_{3} \mathrm{NCs}$ were encapsulated in acrylate-based polymers to form NCs / polymer nano-composite beads, with an average diameter lower than $500 \mathrm{~nm}$. Structural and optical characterizations demonstrated good preservation of the NC properties after the spraydrying despite quite harsh process conditions. Specific acrylate-based polymers were selected in order to match native surface ligands from our NCs. This was necessary to obtain an effective encapsulation within the beads. To evaluate the encapsulated NCs photostability under in-use conditions, bare NCs and encapsulated NCs were deposited on the chip of a blue LED down-converter to compare their luminescence stability. We observed that under continuous blue photon excitation, the NCs / polymer nano-composite beads exhibit a much better resistance to photobleaching compared to bare NCs.
\end{abstract}

\section{INTRODUCTION}

Colloidal lead halide perovskite semiconductor nanocrystals (LHP NCs) have attracted much interest since their first hot-injection synthesis reported in 2015. ${ }^{1}$ LHP NCs exhibit remarkable optical properties: their photoluminescence quantum yield (PLQY) can reach near unity, they possess a narrow emission spectrum which is tunable over the visible spectrum, and have demonstrated great potential for unique photon sources. ${ }^{2}$ Owing to their intrinsic defect tolerance and ease of synthesis, LHP NCs have been employed in many fields of applications, such as light-emitting diodes (LEDs), ${ }^{3,4,5}$ solar cells, ${ }^{6,7}$ cell imaging, ${ }^{8,9}$ single photon emitters,,${ }^{10,11}$ and security bar codes. ${ }^{12,13}$ However, LHP NCs suffer from poor stability due to their low formation energy and strong ionic nature. ${ }^{14,15}$ Particularly, the luminescent properties of LHP rapidly degrade in solid-state under ambient conditions, i.e. in presence of oxygen and moisture, or under in-use conditions with heat or light stress, ${ }^{16,17,18,19}$ limiting their potential integration in devices at the industrial scale.

Since their discovery, tremendous efforts have been made to stabilize the properties of LHP NCs. Various studies have been conducted on the chemical stabilization of the LHP NCs, by ligand engineering, ${ }^{20,21,22}$ or by synthetization of core/shell heterostructures. $^{23,24}$ These routes effectively led to better stability in solution, but still lack of promising results in the solid-state. Different materials were also explored as host matrices to encapsulate and protect LHPs NCs from external stresses, such as polymers. . $^{5,925,26,27,28,29,30,31,32,33,34}$, metal oxides, ${ }^{35,36,37,38}$ metallic salt, ${ }^{39}$ metal organic frameworks, ${ }^{12,40}$ or graphene/2D materials, ${ }^{41,42}$. LHP NCs / polymers composite films were the first materials to be tested, thanks to the simplicity and the soft conditions of polymer processability which suite well to the poor stability of LHP NCs. For example, in 2016, Raja. et al. formed micron thick composite films by simply blending $\mathrm{CsPbBr}_{3} \mathrm{NCs}$ and high-molecular-weight polymers such as polystyrene and acrylate-based polymers. ${ }^{25}$ More recently, Lu et al. used a hydrophobic fluoropolymer to form $100 \mathrm{~nm}$ thick composite films with the same blending method, reaching a high stability in water for temperature imaging in digital microfluidics. ${ }^{34}$ In situ polymerization was also studied, ${ }^{27,28,30,33}$ for example Tong et al. developed an ultraviolet polymerization after a blade coating of a mixture of $\mathrm{CsPbBr}_{3} \mathrm{NCs}$; using monomers as both ligands and solvent, the obtained films showed promising photostability against continuous illumination. ${ }^{30}$

Even if remarkable stability improvements have been made in the past few years for composite NCs / polymeric films, these macroscopic encapsulation approaches are only tailored to a few applications, mainly for optoelectronic devices. Instead of embedding NCs in macroscopic matrices, another approach consists of forming micro- or nano-composite polymeric particles. These composite particles present several advantages ranging from their ability to be dispersed and incorporated in media or other matrices, simplified handling, and additional surface functionalization is possible. Until now, different methods have been developed to form polymeric beads with fluorescent NCs inside, including: swelling/shrinking 
methods, ${ }^{9,43}$ suspension polymerization, ${ }^{44,45}$ electro-spray, ${ }^{46}$ or microfluidic jet-mode breakup. ${ }^{47}$ For LHP NCs, Wei et al. have formed $\mathrm{CsPbBr}_{3} \mathrm{NCs}$ / polystyrene nano- and micro-composite beads by a swelling/shrinking strategy with superior waterresistant properties. Similar approaches have also been developed for nanocomposite LHP NCs / polymers microcomposite fibers. ${ }^{29,31}$

Despite these notable advancements, there is always a need for effective and scalable methods to produce LHP NCs / polymer nano-composite particles. Furthermore, a deeper study of their photo-stability is needed to evaluate their performance and determine their potential as light down-converting materials in LED applications. To achieve this objective whilst proposing a new approach for the fabrication of nano-composite particles with improved stability, we wanted to explore the utilization of a spray-drying method to encapsulate LHP NCs in polymeric beads. This process has been known since the late $19^{\text {th }}$ century $^{48}$ and is currently a cost-effective, facile, and scalable process. ${ }^{49}$ The spray-drying process is widely used in the pharmaceutical, flavor, and food industries. The adoption of this technique is widespread as it permits manufacturers to produce a dry powder from a solution of chemical components by atomization into small droplets dried in a hot zone to obtain solid beads. ${ }^{49,50}$ This technique can serve to simply dry active substances or to encapsulate target molecules, such as drugloaded carrier systems. ${ }^{50,51,52}$ Because spray-drying is suited to sensitive components thanks to its fast drying step (few milliseconds), it seemed interesting to us to encapsulate LHP NCs with this process and measure the potential stability improvements. To the best of our knowledge, only one similar combination had been reported in 2006 by Chu et al., who successfully incorporated CdTe quantum dots in bovine serum albumin for bio medical applications, but the final photostability of their micro-composite beads was not evaluated..$^{53}$

Herein, we report an effective encapsulation method based on a spray-drying process, to produce $\mathrm{Cs}_{\mathrm{PbBr}} \mathrm{NCs} /$ polymers nano-composite beads. We employed acrylate-based polymers and managed to obtain beads within a fine range of drying temperatures. We performed morphological, structural, and optical characterization on the composite beads. The influence of the NCs surface ligands on the encapsulation was of paramount importance, since we show that only $\mathrm{CsPbBr}_{3} \mathrm{NCs}$ with short native ligands were properly encapsulated within the polymeric beads. Spray-dried $\mathrm{CsPbBr}_{3}$ NCs conserved their initial structural properties while the PLQY was much better preserved at solid-state compare to films of bare NCs. The photo-stability of NCs / polymer nano-composite beads was studied using a LED down-converter device with "NCs onchip" deposition. We measured an improved NCs photostability with the spray-drying encapsulation, resulting in a stable green emission that was recorded after $200 \mathrm{~h}$ of continuous photon excitation.

\section{RESULTS AND DISCUSSION}

Because NC surface ligands and polymer matrix interactions play an important role in $\mathrm{NC}$ dispersion, ${ }^{54}$ two syntheses of $\mathrm{CsPbBr}_{3} \mathrm{NCs}$ with different surface ligands were studied to develop the spray-drying polymer encapsulation. First, $\mathrm{CsPbBr}_{3} \mathrm{NCs}$ with long ligands $\left(\mathrm{CsPbBr}_{3}-\mathrm{LL}\right)$ were synthesized following a classical hot-injection synthesis based on the protocol developed by Protesescu et al., ${ }^{1}$ where oleic acid and oleylamine play the role of long alkyl chain stabilizers.
Second, $\mathrm{CsPbBr}_{3} \mathrm{NCs}$ with short ligands $\left(\mathrm{CsPbBr}_{3}-\mathrm{SL}\right)$ were synthesized following a room-temperature synthesis based on the protocol developed by Akkerman et al., ${ }^{7}$ with propionic acid and butylamine as stabilizers.
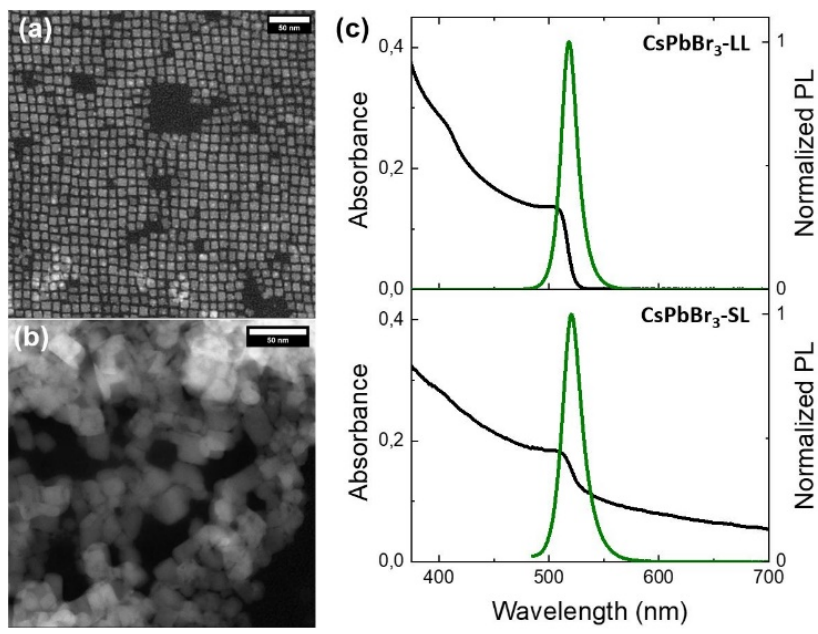

Figure 1. HAADF scanning transmission electron microscopy images of (a) $\mathrm{CsPbBr}_{3}-\mathrm{LL}$ NCs and (b) $\mathrm{CsPbBr}_{3}-\mathrm{SL}$ NCs. (c) Absorption (black line) and emission spectra (green line) of $\mathrm{CsPbBr}_{3}-\mathrm{LL} \mathrm{NCs}$ (top) and $\mathrm{CsPbBr}_{3}-\mathrm{SL}$ NCs (bottom) in toluene solutions.

As shown in Figure 1a and $1 \mathrm{~b}, \mathrm{CsPbBr}_{3}-\mathrm{LL}$ NCs exhibited a cubic shape with an average lateral dimension of $9.1 \pm 1.3 \mathrm{~nm}$ according to HAADF-STEM images, whereas $\mathrm{CsPbBr}_{3}-\mathrm{SL}$ NCs exhibited crystalline domains of $19.6 \pm 6.1 \mathrm{~nm}$ in size, revealing higher size dispersity for the short ligand synthesis. Moreover, while $\mathrm{CsPbBr}_{3}$-LL NCs were well separated from each other on the TEM grid due to the presence of long organic ligands, $\mathrm{CsPbBr}_{3}-\mathrm{SL} \mathrm{NCs}$ were agglomerated since short ligands cannot maintain a steric barrier between NCs. Analyses of high-resolution STEM images confirmed that both types of NCs crystallized in the orthorhombic crystalline structure of $\mathrm{CsPbBr}_{3}$ perovskite (Figure $\mathrm{S} 1$ and S2). The optical properties of the NCs are shown in Figure 1c. The CsPbBr 3 -SL NCs absorbance spectrum illustrates the presence of light scattering, a phenomenon mainly due to the poor colloidal stability of the NCs, since short ligands induced weaker steric barriers than long ligands. ${ }^{55}$ This difference of colloidal stability was clearly identified by the turbidity of the suspension of $\mathrm{CsPbBr}_{3}$-SL NCs after synthesis and purification (Figure S3). The photoluminescence (PL) spectra showed an emission peak centered at 517 and $520 \mathrm{~nm}$ for $\mathrm{CsPbBr}_{3}-\mathrm{LL}$ and $\mathrm{CsPbBr}_{3}-\mathrm{SL}$ NCs respectively, with a full width at half maximum (FWHM) of 18 and $22 \mathrm{~nm}$, respectively. The absolute PLQY was measured at $70-80 \%$ for $\mathrm{CsPbBr}_{3}-\mathrm{LL}$ NCs and $60-70 \%$ for $\mathrm{CsPbBr}_{3}-\mathrm{SL} \mathrm{NCs}$, depending on the synthesis batch.

Figure 2 shows a sketch of the spray-drying process for nano-encapsulation of $\mathrm{CsPbBr}_{3} \mathrm{NCs}$ within polymeric beads. The initial solution feed was composed of $\mathrm{CsPbBr}_{3} \mathrm{NCs}$ and a specific formulation of polymer dissolved in toluene at $4 \mathrm{wt} \%$. Toluene was used as the solvent because of its good compatibility with LHP NCs and its capability to dissolve many commercial hydrophobic polymers. The spray-drying process 


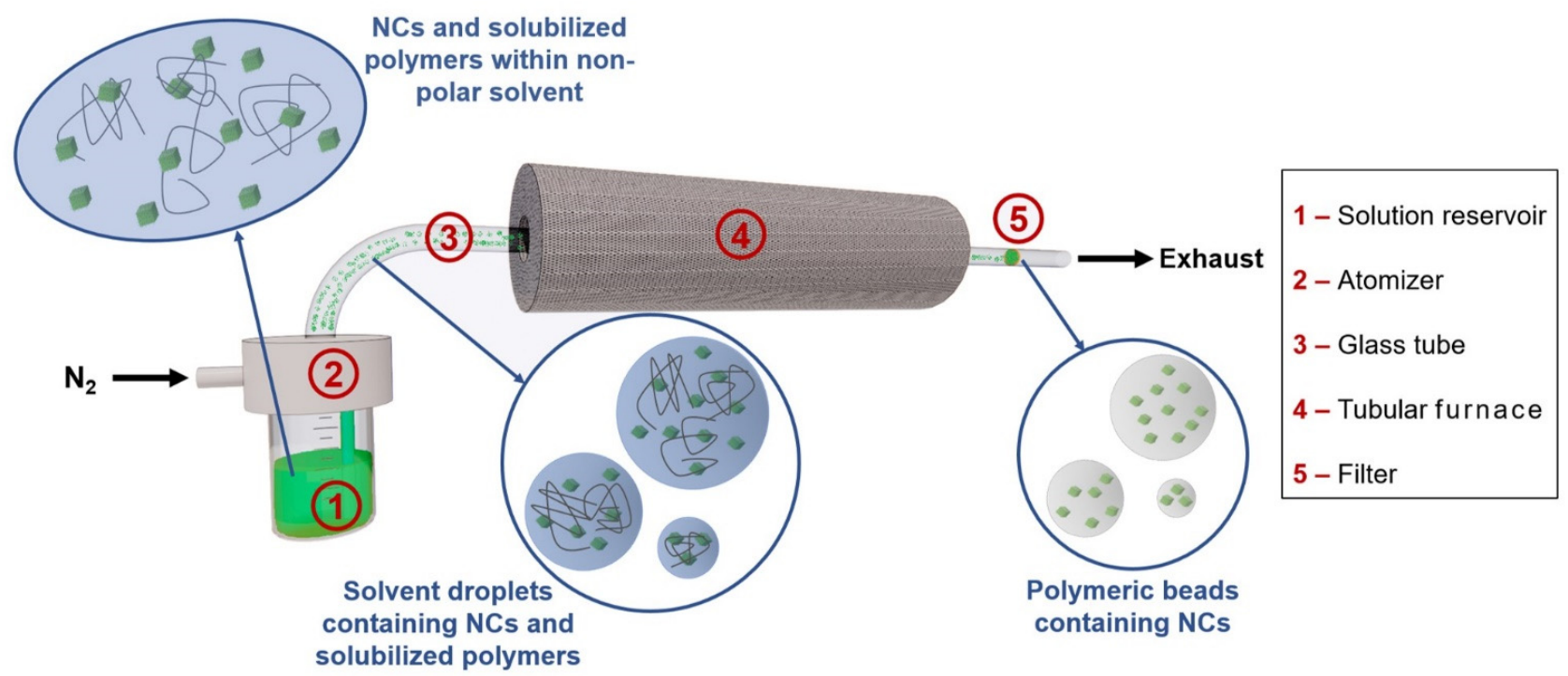

Figure 2. Schematic illustration of the spray-drying process for the nano-encapsulation of $\mathrm{CsPbBr}_{3} \mathrm{NCs}$ in polymeric beads.

can be divided into three main steps. The first step involves the atomization of the solution feed into micrometric droplets. In the second step, these solvent droplets containing the solubilized polymeric chains and $\mathrm{CsPbr}_{3} \mathrm{NCs}$ were pulled along the glass tube by a nitrogen flow and then dried in a hot zone heated by a tubular furnace in the range of $170-290{ }^{\circ} \mathrm{C}$. At this stage, the solvent was quickly evaporated, and the polymer condensed into a spherical shape that encapsulated the NCs. In the last step, the resulting dried polymeric beads containing $\mathrm{CsPbBr}_{3} \mathrm{NCs}$ were collected on a filter. The encapsulation process is very rapid, taking less than 1 second between the first droplet formation and the first dried beads collected on the final filter. We measured a material yield around $50 \%$, corresponding to the weight ratio between the initial compounds (polymers $+\mathrm{NCs}$ ) and the final beads weight collected on the filter. Most of the material loss was due to the dried polymer that remained stuck on the inner glass tube surface. This materials loss is intrinsic to the small-scale spraydrying setup used in this study, higher material yield is expected when using an industrial scale spray-dryer.

Different hydrophobic polymers were tested and each one was evaluated through three main criteria: to obtain solid polymeric beads, to retain the $\mathrm{CsPBBr}_{3} \mathrm{NC}$ photoluminescence properties, and to get an homogeneous NCs dispersion within the beads. In this work, we will only discuss the polymeric formulation with 50:50 in weight of poly(methyl methacrylate) (PMMA) and poly(butyl methacrylate-co-methyl methacrylate) (PBMMA) as it led to the best results among the different formulations tested, mainly in terms of NCs dispersion within the polymeric matrix as it will be discussed below.

We first tested the spray-drying encapsulation of short ligand LHP NCs. Figure 3a shows a SEM image of typical PMMA:PBMMA 50:50 w:w beads obtained by spray-drying encapsulation of $\mathrm{CsPbrr}_{3}-\mathrm{SL}$ NCs with a heating temperature of $170{ }^{\circ} \mathrm{C}$. The obtained polymeric particles presented a spherical shape. As shown in Figure $3 b$, the beads size distribution was found to be very wide, the particle size is in the range of roughly $40 \mathrm{~nm}-2 \mu \mathrm{m}$, with an average diameter of $\sim$ $430 \mathrm{~nm}$, calculated from representative samples with a minimum of 500 beads. Most of the obtained polymeric beads were smaller than $1 \mu \mathrm{m}$ since $90 \%$ of the beads had a diameter lower than $800 \mathrm{~nm}$. It is well known that the size distribution mainly depends on the atomizer technology, ${ }^{56}$ in this work we used an impactor nozzle atomizer type which generated droplets from 0.1 to $5 \mu \mathrm{m}$ in diameter. This broad size distribution can be due to random formation of larger droplets, or to droplet fusion before the drying step. ${ }^{57}$ Such high polydispersity and micrometric size objects can be a problem for further use in applications, such as device integration. Different subsequent sorting techniques have been studied, such as cyclone ${ }^{58}$ or cascade impactor, ${ }^{59}$ and could be used in the future to avoid the presence of large beads and to improve the size dispersity.

Figure $3 \mathrm{c}$ shows typical images under ambient light and UV excitation of the polymeric powder obtained by spray-drying. The tubular furnace temperature was one of the key parameters of the spray-drying encapsulation process. For a tubular furnace temperature at $130{ }^{\circ} \mathrm{C}$ or lower, no powder was collected but instead, a uniform film of polymer was formed on the filter. The solvent evaporation was certainly not complete $\left(\mathrm{T}_{\mathrm{eb}}\right.$ (toluene $)=$ $110^{\circ} \mathrm{C}$ ) and led to an agglomeration of half-liquid half-solid polymers on the filter, which then dried slowly on the membrane to form a uniform film. Even if the tubular temperature was set to $130^{\circ} \mathrm{C}$, the temperature perceived by the droplets within the glass tube is approximately $50^{\circ} \mathrm{C}$ lower than the target temperature. On the opposite side, for a tubular furnace temperature at $290{ }^{\circ} \mathrm{C}$ or higher, a uniform film of polymer was also formed onto the filter but not for the same reason. In this case the formation of the polymeric films was due to beads coalescence. Indeed, the acrylate-based polymers we used in this study have low glass-transition temperatures $\left(\mathrm{T}_{\mathrm{g}, \mathrm{PMMA}}=105{ }^{\circ} \mathrm{C} ; \mathrm{T}_{\mathrm{g}, \mathrm{PBMm}}=52^{\circ} \mathrm{C}\right)$. When exposed to high temperatures, these thermoplastic polymers tend to become more viscous and lose their initial shapes. Figure $3 \mathrm{~d}$ also shows the influence of the tubular furnace temperature on the final PLQY of composite beads containing $\mathrm{CsPbBr}_{3}-\mathrm{SL} \mathrm{NCs}$. The final powder PLQY was $35 \pm 1 \%$ for a process temperature of $170{ }^{\circ} \mathrm{C}$ and dropped to $30 \pm 1 \%$ at $210{ }^{\circ} \mathrm{C}$ and $21 \pm 1 \%$ at 250 ${ }^{\circ} \mathrm{C}$. This trend line is in good agreement with the poor stability of LHPs against thermal stresses, ${ }^{19}$ moreover, the PLQY drop might have been caused by ligand desorption during the spray- 
(a)

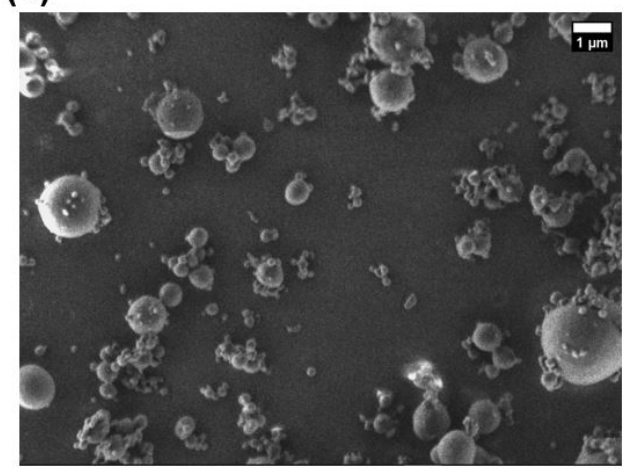

(c)

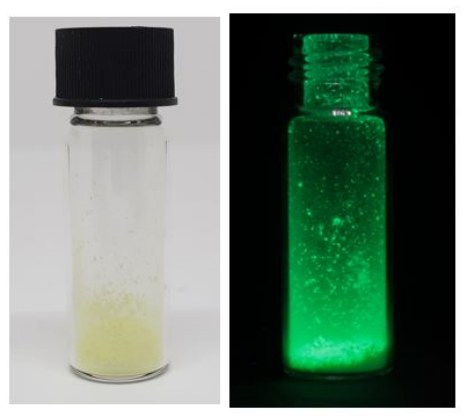

(b) 80

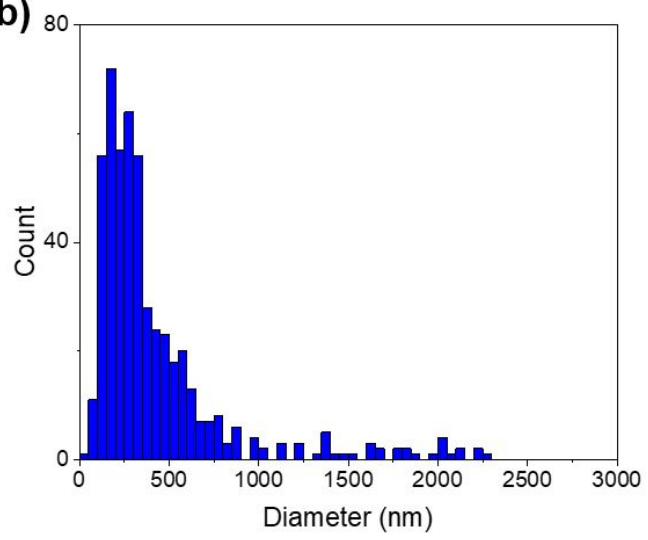

(d)

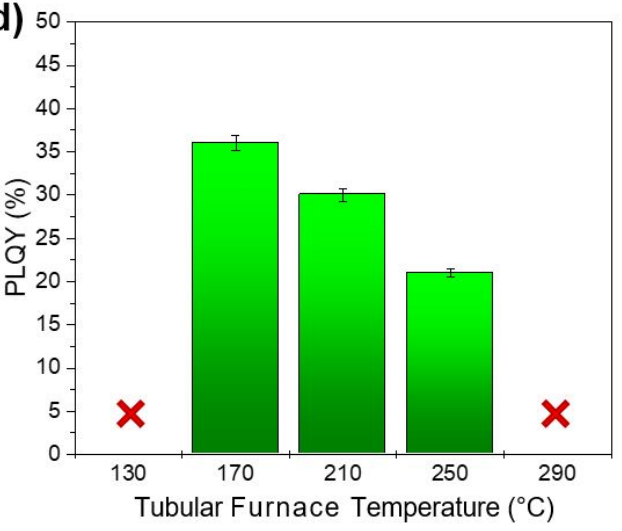

Figure 3. PMMA:PBMMA 50:50 w: w beads after $170^{\circ} \mathrm{C}$ spray-drying encapsulation of CsPbBr3-SL NCs: (a) scanning electron microscopy image, (b) size distribution, (c) a picture of powder under ambient light (left) and $405 \mathrm{~nm}$ UV excitation (right), and (d) PLQY depending on the tubular furnace temperature, red cross indicates that no beads were obtained at this temperature.

drying process. PLQY variations compared to bare NCs are discussed below. Similar results on the morphology, size distribution and temperature dependency on PLQY were obtained for $\mathrm{CsPbBr}_{3}-\mathrm{LL} \mathrm{NCs}$ spray-drying encapsulation (Figure S4 and S5). The size distribution was very similar, showing that it is mostly polymer and process dependent. The PLQY of the spray-dried NCs with long ligands also decreased with process temperature increasing, however the loss was smaller compare to short ligands, probably because long ligands can desorb less easily. ${ }^{7}$

The NCs dispersion within the beads was further investigated by STEM analysis. HAADF STEM images clearly indicated that $\mathrm{CsPbBr}_{3}-\mathrm{LL}$ NCs (Figure 4a) after spray-drying were located on the polymeric beads surface and were not encapsulated. To disperse the NCs within the matrix was the most complicated part of this work, indeed we did not succeed in properly encapsulating $\mathrm{CsPbBr}_{3}-\mathrm{LL} \mathrm{NCs}$ with any tested polymers as NCs were always found on the beads surface. We hypothesized that the interaction between acrylate polymeric chains and long ligands of $\mathrm{CsPbBr}_{3}-\mathrm{LL}$ NCs (oleic acid and oleylamine) were not strong enough to prevent separation between the solidifying polymeric phase and the NCs during the solvent evaporation. The polarity difference between long alkyl nonpolar surface ligands of $\mathrm{CsPbBr}_{3}-\mathrm{LL}$ and more polar acrylate polymers may explain their poor affinity.

For spray-dried $\mathrm{CsPbBr}_{3}-\mathrm{SL}$ NCs, HAADF STEM images revealed that NCs were inside the polymeric beads (Figure 4b), which explicitly demonstrated the $\mathrm{CsPbBr}_{3}-\mathrm{SL} \mathrm{NCs}$ encapsulation with the spray-drying process. We believe that in solution the affinity between $\mathrm{CsPbBr}_{3}-\mathrm{SL} \mathrm{NCs}$ and PMMA:PBMMA is increased due to better interaction between ligands and polymeric chains, which consequently prevents any phase separation during the solvent evaporation and polymer solidification. In this case, NCs surface ligands and polymeric matrix had similarities in their chemical nature: propionic acid and butylamine for the NC surfaces; grafted butyl groups for the acrylate polymers. Raino et al. suggested in 2019 to improve the interaction between polymers and ligands by using grafted polymers with specific alkyl chains to match the surface chemistry of $\mathrm{CsPbBr}_{3} \mathrm{NCs}^{32}$ which is in line with our observations in terms of NCs-polymers affinity.

To highlight the influence of the nano-encapsulation on the $\mathrm{CsPbBr}_{3} \mathrm{NCs}$ properties, PL, PLQY and XRD analyses were performed on spray-dried NCs with long and short ligands and were compared to corresponding bare $\mathrm{Cs}_{\mathrm{PbBr}} \mathrm{NCs}$ in solution or in film. NC solutions were dispersed in toluene and NC films were made by drop casting NC solutions on a glass substrate under ambient conditions and allowed to completely dry before analysis. PL peaks of $\mathrm{NC}$ films with bare $\mathrm{CsPbBr}_{3}-\mathrm{LL}$ and $\mathrm{CsPbBr}_{3}$-SL NCs were respectively red-shifted by $9 \mathrm{~nm}$ and 10 $\mathrm{nm}$ compared to the PL peaks in solution (Figure 5c). An increase in FWHM of $6 \mathrm{~nm}$ and $8 \mathrm{~nm}$ is also observed, respectively. PL redshift and FWHM increase may be attributed to NCs aggregations and bulk-like contribution. ${ }^{60}$ These observations indicated a partial degradation of the NCs PL properties in solid-state after deposition, which is one of the numerous known stability issues for such materials. ${ }^{2}$ The same NCs at solid state but after the spray-drying process exhibited a 

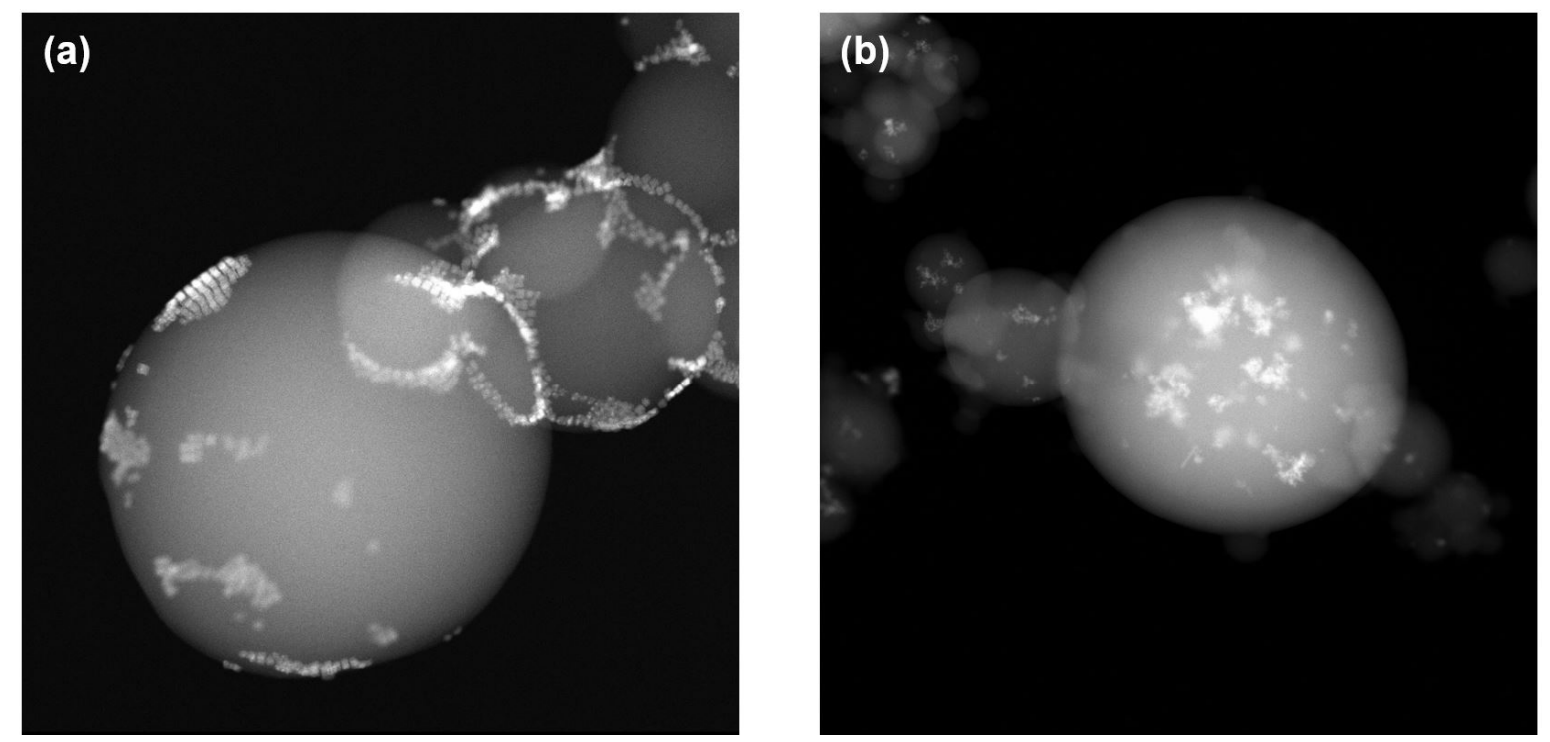

Figure 4. HAADF STEM images of (a) $\mathrm{CsPbBr}_{3}-\mathrm{LL}$ NCs and (b) $\mathrm{CsPbBr}_{3}-\mathrm{SL}$ NCs both $170{ }^{\circ} \mathrm{C}$ spray-dried with PMMA/P(BM)MA 50/50 w/w.

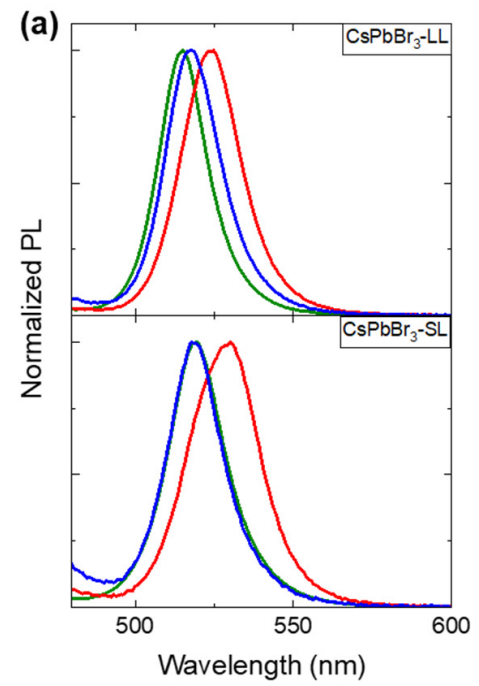

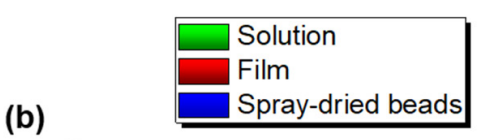

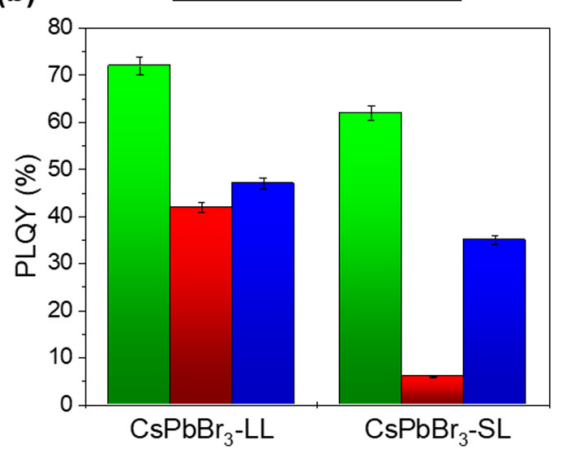

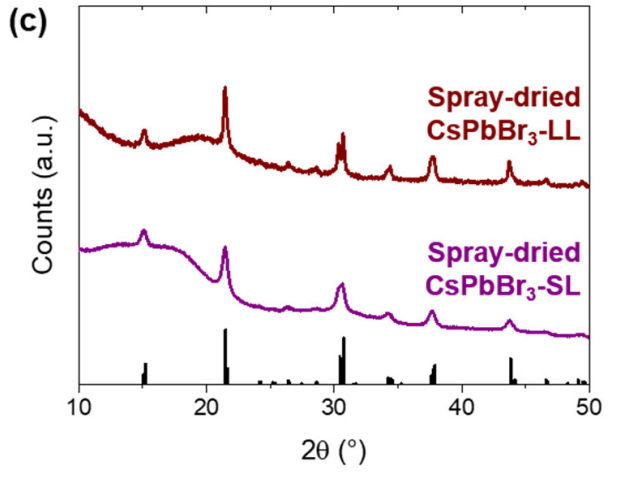

Figure 5. (a) Emission spectra and (b) PLQY of CsPbBr3-LL and CsPbBr3-SL NCs: in solution (green), in films obtained by drop casting of bare $\mathrm{NCs}$ (red) and after spray-drying process at $170{ }^{\circ} \mathrm{C}$ (blue). (c) XRD patterns of spray-dried CsPbBr $3-\mathrm{LL} \mathrm{NCs}$ (brown) and $\mathrm{CsPbBr} 3-\mathrm{SL}$ NCs (purple) with XRD pattern of orthorhombic $\mathrm{CsPbBr}_{3}$ ICSD 98-009-7851 (black).

different behavior. Compare to PL properties in solution, spraydried $\mathrm{CsPbBr}_{3}$-LL NCs PL maximum was red-shifted by only 2 $\mathrm{nm}$ and no shift was observed for spray-dried $\mathrm{CsPbBr}_{3}-\mathrm{SL} \mathrm{NCs}$. Moreover, the FWHM were unchanged after spray-drying for both $\mathrm{CsPbBr}_{3}-\mathrm{LL}$ and $\mathrm{CsPbBr}_{3}-\mathrm{SL} \mathrm{NCs}$, indicating a good preservation of color purity and a better spatial separation of NCs compared to films with bare NCs. Thus, because the PL properties are linked to the NCs integrity, we assumed that the spray-drying encapsulation prevented more efficiently the NCs aggregation in solid-state, particularly in the case of encapsulated $\mathrm{CsPbBr}_{3}-\mathrm{SL} \mathrm{NCs}$.

Concerning PLQY analyses (Figure 5b), when comparing NCs in solution and films of bare NCs, PLQY dropped from 72 $\pm 2 \%$ to $42 \pm 1 \%$ for $\mathrm{CsPbBr}_{3}-\mathrm{LL}$ NCs, and PLQY dropped even more drastically from $62 \pm 2 \%$ to $8 \pm 1 \%$ for $\mathrm{CsPbBr}_{3}-$ SL NC. The loss of PLQY for LHPs NCs in solid-state is not totally understood but it was demonstrated on bulk LHPs that grain boundaries induced more non-radiative exciton recombination, limiting bulk LHP PLQY. ${ }^{61}$ Thus, the important loss of PLQY for bare $\mathrm{CsPbBr}_{3}-\mathrm{SL}$ NCs film may be directly linked to the high quantity of grain boundaries induced by the use of short ligands which did not prevent NCs aggregation during solvent evaporation. ${ }^{7}$ This hypothesis is greatly supported by the STEM analyses (Figure 1b). Now, when comparing NCs in solution and after spray-drying, PLQY dropped from $72 \pm 2 \%$ to $47 \pm 1 \%$ for $\mathrm{CsPbBr}_{3}-\mathrm{LL} \mathrm{NCs}$, and PLQY dropped from $62 \pm 2 \%$ to $35 \pm 1 \%$ for $\mathrm{CsPbBr}_{3}$-SL NCs. The difference of PLQY conservation between NCs films and spray-dried nanocomposites was weak for $\mathrm{CsPbBr}_{3}-\mathrm{LL} \mathrm{NCs}$, but for $\mathrm{CsPbBr}_{3}-\mathrm{SL} \mathrm{NCs}$, the conservation of the initial solution PLQY $(62 \pm 2 \%)$ is significantly improved after spray-drying encapsulation $(35 \pm 1 \%)$ compare to NCs film $(8 \pm 1 \%)$. These observations indicated a reduced number of aggregated NCs for the encapsulated $\mathrm{CsPbBr}_{3}-\mathrm{SL} \mathrm{NCs}$, in good agreement with PL 


\section{(b)}
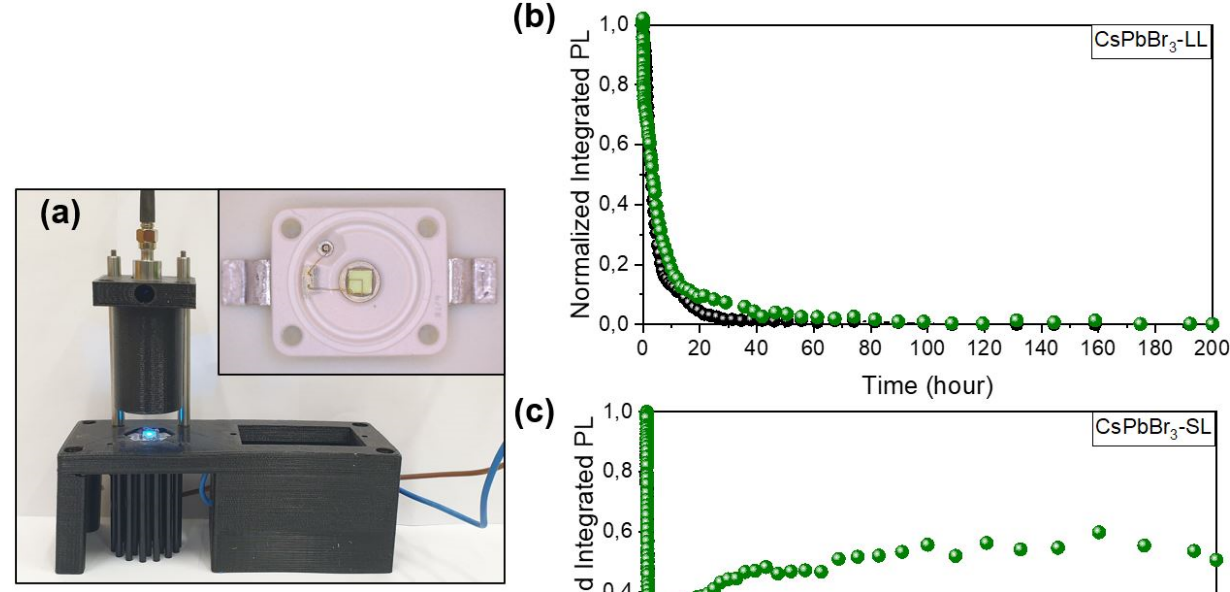

(c)

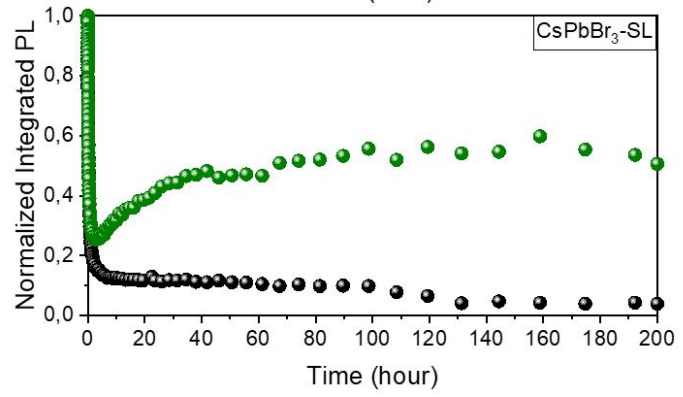

(d)

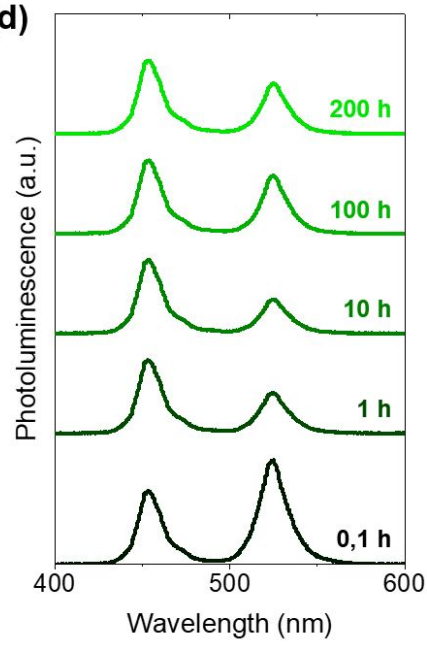

Figure 6. Photostability over time of bare NCs and spray-dried NCs under continuous illumination $\left(0.1 \mathrm{~W} / \mathrm{cm}^{2}\right.$; blue LED $\left.455 \mathrm{~nm}\right)$ in an onchip configuration. (a) Images of the setup (inset: NCs on-chip). Normalized integrated PL evolution over time of (b) CsPbBr3-LL NCs and (c) $\mathrm{CsPbBr}_{3} \mathrm{SL} \mathrm{NCs}$ with bare NCs (black points) and spray-dried NCs (greens points). (d) Evolution of the corresponding emission spectrum of the LED down-converter with spray-dried CsPbBr3-SL NCs.

analyses and STEM images. In general, the loss of PLQY during the spray-drying process may also have been caused by NCs surface ligands lost, which are known to have a very labile nature. Furthermore, the better PLQY conservation for spraydried $\mathrm{CsPbBr}_{3}-\mathrm{SL}$ NCs compare to bare NCs films strongly supported the benefit of the encapsulation.

Both spray-dried $\mathrm{CsPbBr}_{3}-\mathrm{LL}$ and $\mathrm{CsPbBr}_{3}-\mathrm{SL}$ NCs XRD patterns exhibited the expected orthorhombic crystalline structure of $\mathrm{CsPbBr}_{3}$ perovskite. ${ }^{62,63}$ No additional phase formation due to thermal degradation is observed, which is usually a limiting aspect for LHPs. ${ }^{19}$ In other words, the encapsulation by spray-drying did not modify the structural properties of $\mathrm{CsPBr}_{3} \mathrm{NCs}$.

The spray-drying encapsulation in these specific conditions, not only preserved the initial morphological and structural properties of $\mathrm{CsPbr}_{3}-\mathrm{SL} \mathrm{NCs}$, but also improved the stability of their optical properties (PL, PLQY) compared to bare NCs in solid-state, which is a crucial problem for many applications. Despite these encouraging results, the final PLQY of $35 \%$ of the $\mathrm{CsPbBr}_{3}$-SL NCs / polymers nano-composite beads is relatively low compare to previous reported works on green emitting LHPs NCs / polymer composite films with good stability. ${ }^{28,30}$ To enhance the NC emission properties, many surface treatments have been explored in the literature reaching higher PLQY and stability, ${ }^{20,21}$ most of these studies have been conducted on $\mathrm{CsPbBr}_{3}$-LL NCs. We believe that a similar postsynthesis surface passivation on $\mathrm{CsPbr}_{3}-\mathrm{SL}$ with appropriate short surface stabilizer (for example zinc bromide or tetrabutylammonium bromide) to keep the NCs inside the beads, would enhance the PLQY of bare NCs. In that way, the nanocomposites beads PLQY should directly benefit from the improvement of the NCs properties, with a better final PLQY. This aspect is under current investigation in our laboratories.

To evaluate the benefit of the spray-drying encapsulation on the $\mathrm{CsPbBr}_{3} \mathrm{NCs}$ photo-stability, we followed the evolution of their PL emission under a continuous blue excitation in a LED down-converter device. Figure 6a shows the setup used for photo-stability measurements in ambient conditions. The NCs were excited by a blue LED $(\lambda=455 \mathrm{~nm})$ with a surface power density of $0.1 \mathrm{~W} / \mathrm{cm}^{2}$, similar to industrial test conditions for backlighting materials in LCD displays. The bare NCs or spraydried NCs were deposited on the blue-LED with an on-chip configuration, i.e. by drop-casting the NCs solutions directly on the chip (inset in Figure 6a). The emission stability of $\mathrm{CsPbr}_{3}$ $\mathrm{NCs}$ was evaluated by tracing the evolution of the integrated green PL signal.

For bare $\mathrm{CsPbBr}_{3}-\mathrm{LL}$ NCs (black dots on Figure $6 \mathrm{~b}$ ), the green emission decreased rapidly and continuously when exposed to the blue excitation, indeed the normalized integrated PL dropped to 0.1 after only $13 \mathrm{~h}$ and to almost 0 after 50 hours. Such decrease in PL is generally attributed to a poor resistance against photobleaching and is in line with similar reported observations. ${ }^{5,18}$ The same degradation behavior was recorded for spray-dried $\mathrm{CsPbBr}_{3}$-LL NCs (green dots on Figure 6b), even if a small normalized PL of 0.1 is retained after $30 \mathrm{~h}$. The composite beads behaved like bare NCs because $\mathrm{CsPbBr}_{3}-\mathrm{LL}$ NCs were not encapsulated in polymeric beads.

In the same way, green emission of bare $\mathrm{CsPbBr}_{3}-\mathrm{SL} \mathrm{NCs}$ decreased rapidly and continuously (black dots on Figure 6c), the normalized integrated PL intensity dropped to 0.1 after 55 hours. However, the green emission signal of the spray-dried $\mathrm{CsPbrr}_{3}-\mathrm{SL} \mathrm{NCs}$ was far more intense over time than the bare NCs (green dots on Figure 6c). Specifically, the normalized PL decreased down to 0.25 in the first few hours, but then slowly recovered and stabilized to an average value of $0.52 \pm 0.04$ from 50 to 200 hours. This better resistance to photobleaching demonstrated that the polymeric beads acted as a barrier against external environments. Likely the hydrophobic matrix limited the diffusion of ambient oxygen and moisture into the bead and slow down the photobleaching of $\mathrm{CsPBr}_{3} \mathrm{NCs}$. These results highlighted the benefits of the spray-drying encapsulation 
process on $\mathrm{CsPbBr}_{3} \mathrm{NCs}$, indeed when the $\mathrm{CsPbBr}_{3}-\mathrm{SL} \mathrm{NCs}$ were truly encapsulated we measured a photo-stability improvement.

As mentioned, the green emission of the spray-dried $\mathrm{CsPbBr}_{3}-\mathrm{SL} \mathrm{NCs}$ exhibited a specific behavior during the first hours of the experiment, the PL first decreased, then slowly increased, and finally stabilized for several hours (Figure $6 \mathrm{~d}$ or in logarithmic scale Figure S6). Because the blue excitation power density was constant (minor variations compare to green variations), these PL variations were directly linked to NCs PLQY variations and thus indicated changes in the ratio between radiative and non-radiative recombination, especially for the first PL quenching and the following PL brightening. We note that for bare $\mathrm{CsPbBr}_{3} \mathrm{NCs}$, only photobleaching due to photo-degradation was observed, thus PL quenching and brightening were probably induced by the spray-drying encapsulation. Previous studies on LHP materials have observed similar PL behavior. ${ }^{64,65,66}$ Galisteo-Lopez et al., ${ }^{64}$ observed strong PL photoactivation under continuous similar blue light excitation on hybrid organic-inorganic LHP bulk film. However, they did not observe early PL quenching, only a final photobleaching mostly due to moisture degradation. In the same way, Lorenzon et al. ${ }^{66}$ studied the PL behavior of bare $\mathrm{CsPbBr}_{3} \mathrm{NCs}$ under different environmental conditions, they pointed out that PL quenching occurred with the presence of nonradiative defects, especially surface states and dangling bonds, leading to photogenerated carrier trapping. Based on these previous studies on LHP materials and others on Cd-based quantum dots, ${ }^{67,68,69}$ we assumed that in our case, the first PL quenching event was due to an increasing amount of nonradiative recombination due to carrier trapping. This might have been amplified by the creation of surface defects caused by ligands loss or ligands displacement during the spray-drying process. The following slow brightening indicates an increasing amount of radiative recombination compare to non-radiative, possibly due to trap state passivation. However, to fully understand this competition between PL quenching and brightening, further experiments of photostability under various atmospheres and deeper PL analyses (such as fluorescence lifetime) should be performed to get a better understanding regarding the impact of the polymer matrix on the PL behavior of the encapsulated NCs.

On-chip configurations are known to provide harsh test conditions with high thermal and optical exposure. ${ }^{70}$ In our case, the thermal stresses were limited because sample local temperature was kept at $20-30{ }^{\circ} \mathrm{C}$ during the photo-stability measurements. This was achieved thanks to the relatively low light-power excitation combined with the use of a metal heatsink in our setup. However, the current performances of the composite beads might be even more interesting for less stressful applications such as on-edge or on-surface NCs/LED configurations for backlighting. ${ }^{71}$

\section{CONCLUSION}

We have developed a new method to encapsulate $\mathrm{CsPbBr}_{3}$ NCs within nanometric polymeric beads with a spray-drying process. The combination of acrylate polymers with specific chemical groups (PMMA and PBMMA) matching the short ligands at the surface of the $\mathrm{CsPBr}_{3}-\mathrm{SL} \mathrm{NCs}$ has allowed us to obtain NCs encapsulated within the beads. Through the spraydrying process, we managed to retain the optical and structural properties of the starting $\mathrm{CsPbBr}_{3}-\mathrm{SL} \mathrm{NCs}$. The nano- composite $\mathrm{CsPbBr}_{3}$-SL NCs / polymer beads exhibited a PLQY of $35 \%$ and an improved photo-stability at solid-state regarding to the bare $\mathrm{CsPbBr}_{3}-\mathrm{SLNCs}$. Indeed, we measured a stable NCs emission under in-use conditions with a LED down-converter, making these spray-dried NCs promising candidates for lightconverting materials. We believe that the optical properties and the photo-stability of $\mathrm{CsPbBr}_{3} \mathrm{NCs}$ encapsulated by spraydrying process could be rapidly improved in the future by determining the right NCs surface passivation in the plethora of existing literature. Furthermore, efforts need to be done to reduce the polydispersity of the polymeric beads, and the use of different atomization or size-sorting techniques should help to achieve this objective. The synthesized nano-composite beads in this study could be used directly as final materials, or further incorporated in other types of matrix, or even functionalized. Thus, they may be used for many fields of application in the future, in particular for display applications, biological markers and security encoding.

In a more general context, there is room to explore the spray-drying nano-encapsulation of different types of nanocrystals (fluorescent, plasmonic, magnetic, etc.) in polymeric beads. The spray-drying process should offer a way to synthesize such nano-composite particles with a versatile, inexpensive, and scalable method, thus paving the way for industrialization.

\section{METHODS}

Materials. Lead bromide $\left(\mathrm{PbBr}_{2}, 98 \%\right)$, cesium carbonate $\left(\mathrm{Cs}_{2} \mathrm{CO}_{3}\right.$, 99\%), oleic acid (OA, 90\%), poly(methyl methacrylate) (PMMA, $\left.\mathrm{M}_{\mathrm{w}}=120000 \mathrm{~g} \cdot \mathrm{mol}^{-1}\right)$, poly(butyl methacrylate-co-methyl methacrylate) (P(BM)MA, $\mathrm{M}_{\mathrm{w}}=$ 150000 g. $\mathrm{mol}^{-1}$ ) and n-heptane (HEP, $99 \%$ ) were purchased from Sigma-Aldrich. Toluene (99.8 \%), n-hexane (HEX, 95\%) were purchased from Carlo Erba. 1-octadecene (ODE, $90 \%$ ) and oleylamine (OAm, $90 \%$ ) were purchased from Acros. Propionic acid (PrAc, 99.0\%) was purchased from TCI. nbutylamine (BuAm, 98\%) was purchased from Alfa Aesar. Propanol-2 (IPrOH, 98\%) was purchased from VWR.

Synthesis of $\mathrm{CsPbBr}_{3}-\mathbf{L L ~ N C s}$. The synthesis of $\mathrm{CsPbBr}_{3}-$ LL NCs was adapted from Protesescu et al. ${ }^{1} 1.2 \mathrm{~g}$ of $\mathrm{Cs}_{2} \mathrm{CO}_{3}$ (3.7 mmol), $3.6 \mathrm{~mL}$ of OA $(18.8 \mathrm{mmol})$ and $45 \mathrm{~mL}$ of ODE were introduced in a $100 \mathrm{~mL}$ three-neck round bottom flask and heated at $110^{\circ} \mathrm{C}$ under vacuum for 1 hour. The mixture was then heated to $130^{\circ} \mathrm{C}$ under nitrogen until the cesium oleate (Cs-OA) formation was completed. The Cs-OA solution was kept at $120^{\circ} \mathrm{C}$ to avoid solidification. In another $100 \mathrm{~mL}$ three-neck round bottom flask, $0.330 \mathrm{~g}$ of $\mathrm{PbBr}_{2}(0.9 \mathrm{mmol})$ and $30 \mathrm{~mL}$ of ODE were dried under vacuum for 1 hour at $120^{\circ} \mathrm{C}$. Then, $3 \mathrm{~mL}$ of OA and $3 \mathrm{~mL}$ of OAm were added at $120^{\circ} \mathrm{C}$ under vacuum, the solution was heated for 30 additional minutes. After complete solubilization of $\mathrm{PbBr}_{2}$, the mixture was heated at $180^{\circ} \mathrm{C}$ under nitrogen with a vigorous stirring. Once the desired temperature was reached, $4.8 \mathrm{~mL}$ of Cs-OA $(0.8 \mathrm{mmol})$ solution at $120^{\circ} \mathrm{C}$ was quickly injected. After $15 \mathrm{~s}$ the reaction was rapidly quenched by removing the heating mantle and cooling the flask with an ice water bath. For the purification step, the crude solution was centrifuged at a speed of $9000 \mathrm{rpm}$ for 10 min. The supernatant was then discarded, and the precipitate was dispersed in $6 \mathrm{~mL}$ of toluene. The solution was centrifuged once more at a speed of $2000 \mathrm{rpm}$ for $4 \mathrm{~min}$ and the supernatant was kept while the precipitate was discarded to remove the non- 
stable nanocrystals. The obtained $\mathrm{CsPbBr}_{3}-\mathrm{LL}$ NCs solution was stored under ambient conditions.

Synthesis of CsPbBr3-SL NCs. The protocol synthesis of $\mathrm{CsPbBr}_{3}-\mathrm{SL} \mathrm{NCs}$ was adapted from Akkerman et al. ${ }^{7} \mathrm{~A}$ precursor solution of cesium propionate (Cs-PrA) at $2 \mathrm{M}$ was prepared by dissolving $326 \mathrm{mg}$ of $\mathrm{Cs}_{2} \mathrm{CO}_{3}$ in $1 \mathrm{~mL}$ of propionic acid at room temperature. Another precursor solution of $\mathrm{PbBr}_{2}$ at $0.25 \mathrm{M}$ was prepared by dissolving $184 \mathrm{mg}$ of $\mathrm{PbBr}_{2}$ in $2 \mathrm{~mL}$ mixture of PrAc:IPrOH:BuAm with a 1:1:1 volume ratio. Afterward, $6 \mathrm{~mL}$ of hexane, $3 \mathrm{~mL}$ of IPrOH and $27 \mu \mathrm{L}$ of CsPrA were added in a $25 \mathrm{~mL}$ round bottom flask. The mixture was stirred vigorously under ambient conditions (temperature and atmosphere) and $600 \mu \mathrm{L}$ of $\mathrm{PbBr}_{2}$ solution was quickly injected. The solution immediately turned to green due to the formation $\mathrm{CsPbBr}_{3}-\mathrm{SL} \mathrm{NCs}$. The crude solution was centrifuged at $1000 \mathrm{rpm}$ for $2 \mathrm{~min}$, then the supernatant was discarded and the NCs were dispersed in $6 \mathrm{~mL}$ of toluene. The obtained $\mathrm{CsPbBr}_{3}-\mathrm{SL}$ NCs solution was stored under ambient conditions.

Spray-Drying Encapsulation. Typically, $900 \mu \mathrm{L}$ of $\mathrm{CsPbBr}_{3}-\mathrm{LL}$ or $\mathrm{Cs}_{\mathrm{PbBr}}-\mathrm{SL}$ NCs of as prepared solutions were mixed with $6 \mathrm{~mL}$ of an acrylate polymer solution $(4 \mathrm{wt} \%$ of PMMA:P(BM)MA 50:50 dissolved in toluene) in a specific vial. We estimated the NCs weight concentration to be around $0.2 \mathrm{wt} \%$. The solution was stirred for 1 hour to ensure a good NCs dispersion in the polymer solution. The temperature of the tubular furnace was set at a temperature between 170 and 290 ${ }^{\circ} \mathrm{C}$ and the nitrogen pressure of the atomizer was set at 1.5 bar. Note that the perceived temperature inside the glass tube is around $50{ }^{\circ} \mathrm{C}$ lower than the tubular furnace temperature. The $\mathrm{NCs} /$ polymer solution was then plugged to the atomizer, the vacuum pump was turned $\mathrm{ON}$ and the nitrogen valve of the atomizer was immediately opened to initiate the atomization of the initial solution into a mist of droplets. Consequently, the mist was allowed to pass through the tubular furnace for solvent evaporation. During the process, the NCs / polymer solution continued to be atomized while the spray dried NCs were collected onto the hydrophilic polytetrafluoroethylene filter $(0.22 \mu \mathrm{m})$ placed beforehand at the outlet of the furnace. Once the solution was totally atomized $(\sim 5 \mathrm{~min})$, the nitrogen valve, tubular furnace and vacuum pump were turned off. The dried powder of NCs / polymers composite collected on the filter was transferred and stored in a closed vial under ambient condition.

Preparation of LED Down-Converters. The "on-chip" configuration was used to evaluate the performance of $\mathrm{CsPBr}_{3}$ NCs in a light-emitting diode (LED) down-converter, with an OSRAM "Deep-blue LED W5SM Golden Dragon" as the blue excitation source. The powder of spray dried NCs was dispersed and sonicated in heptane. $2 \mu \mathrm{L}$ of the suspension was then deposited directly on the blue LED chip by drop-casting to form a uniform film of spray-dried $\mathrm{CsPbBr}_{3} \mathrm{NCs}$ after solvent evaporation. For bare $\mathrm{CsPbBr}_{3} \mathrm{NCs}, 2 \mu \mathrm{L}$ of the solution was directly deposited on-chip.

Photoluminescence Quantum Yield Measurement. The PL QY of the spray-dried NCs were measured with an integrating sphere spectrometer (Quantarus-QYPlus from Hamamatsu) and with thin sample to minimize diffusion and reabsorption effects. In order to be as close as possible to real application conditions, we used the same amount of powder as for the preparation of LED down-converters.

Photo-Stability. Photo-stability measurement were carried out under ambient conditions. The commercial blue LED had an excitation wavelength of $455 \mathrm{~nm}$ and was used to optically pump the $\mathrm{CsPbBr}_{3} \mathrm{NCs}$ on-chip. The LED was powered with a DC current supply (LakeShore 101) at $1 \mathrm{~mA}$ to generate a surface power density of $0.1 \mathrm{~W} / \mathrm{cm} 2$. Indeed, for this working current we measured a light-power of $1.1 \mathrm{~mW}$, divided by the 1 $\mathrm{mm}^{2}$ LED-chip surface we obtained a light power density of about $0.1 \mathrm{~W} / \mathrm{cm}^{2}$. The LED was mounted with thermal paste on a printed circuit board attached to a cooler. The emitted signal from the on-chip NCs was collected by an optical fiber and detected with a spectrometer (UV-VIS OCEAN OPTICS STS) to obtain the emission spectrum of the LED down-converter. The emission stability of $\mathrm{CsPbBr}_{3}$ NCs was evaluated by integrating the green PL signal over time.

Instrumentation. TEM/STEM observations were made on a Titan Themis 200 microscope (FEI/ Thermo Fischer Scientific) equipped with a geometric aberration corrector on the probe. The observations were made at $200 \mathrm{kV}$ with a probe current of about $50 \mathrm{pA}$ and a half-angle of convergence of 17 mrad. HAADF-STEM images were acquired with a camera length of $110 \mathrm{~mm}$ (inner/outer collection angles were respectively 69 and $200 \mathrm{mrad}$ ). Scanning electron microscopy (SEM) images were obtained with a JEOL JSM-7800F Prime for morphological characterization of the polymeric beads. Xray powder diffraction (XRD) patterns were recorded with an Empyrean diffractometer from Malvern-Panalytical equipped with a monochromatized $\mathrm{Cu} \mathrm{K} \alpha$ radiation $(\lambda=1.540598 \AA)$ and a PIXcel detector. The photoluminescence quantum yield (PLQY) of NCs was determined (with 5\% of error bar) by using the Quantaurus-QYPlus UV-near-infrared absolute photoluminescence quantum yield spectrometer from Hamamatsu, with $\lambda_{\text {excitation }}=460 \mathrm{~nm}$. UV-visible absorption spectra were recorded on an Agilent Technologies Cary 60 UV-visible single-beam spectrometer. For NC solution, photoluminescence (PL) spectra were measured on a JASCO spectrofluorometer FP 8500, with $\lambda_{\text {excitation }}=350 \mathrm{~nm}$. For film and powder, PL spectra were recorded with the Hamamatsu PLQY spectrometer.

\section{ASSOCIATED CONTENT}

Supporting Information. The Supporting Information is available free of charge via the Internet at http://pubs.acs.org

High resolution STEM, NC suspension pictures, SEM morphology analyses, photostability data.

\section{AUTHOR INFORMATION}

\section{Corresponding Author}

* Félix Boussoufi: fe.boussoufi@gmail.com

\section{Author Contributions}

FB designed and conducted experiments, analyzed data, and wrote the paper. MP analyzed data and finalized the paper. MD and AK designed the spray-drying process. GP conducted microscopic observations. GP and BD supervised the project and acquired funding. All authors have given approval to the final version of the manuscript.

\section{Funding Sources}

This work was supported by the French RENATECH network, the Project TEMPOS (10-EQPX-0050) of the French National Research Agency (ANR) and Nexdot.

\section{Notes}

The authors declare no competing financial interest. 


\section{ACKNOWLEDGMENT}

We acknowledge Sophie Nowak for XRD analysis, Delphine Martin for assistance on Sketchup software, Edgar Cao and Sebastien Dreyfuss for proofreading of the manuscript.

\section{ABBREVIATIONS}

FWHM, full width at half maximum; LED, light-emitting diode; LHP, lead halide perovskite; LL, long ligand; NC, nanocrystal; PL, photoluminescence; PLQY, photoluminescence quantum yield; PMMA, poly(methyl methacrylate); P(BM)MA, poly(butyl methacrylate-co-methyl methacrylate); SEM, scanning electron microscope; SL, short ligands; STEM, scanning transmission electron microscope; XRD, X-ray diffraction

\section{REFERENCES}

(1) Protesescu, L.; Yakunin, S.; Bodnarchuk, M. I.; Krieg, F.; Caputo, R.; Hendon, C. H.; Yang, R. X.; Walsh, A.; Kovalenko, M. V. Nanocrystals of Cesium Lead Halide Perovskites ( $\mathrm{CsPbX} 3, \mathrm{X}=\mathrm{Cl}, \mathrm{Br}$, and I): Novel Optoelectronic Materials Showing Bright Emission with Wide Color Gamut. Nano Lett. 2015, 15 (6), 3692-3696. https://doi.org/10.1021/n15048779.

(2) Shamsi, J.; Urban, A. S.; Imran, M.; De Trizio, L.; Manna, L. Metal Halide Perovskite Nanocrystals: Synthesis, PostSynthesis Modifications, and Their Optical Properties. Chem. Rev. 2019, 119 (5), 3296-3348. https://doi.org/10.1021/acs.chemrev.8b00644.

(3) Congreve, D. N.; Weidman, M. C.; Seitz, M.; Paritmongkol, W.; Dahod, N. S.; Tisdale, W. A. Tunable Light-Emitting Diodes Utilizing Quantum-Confined Layered Perovskite Emitters. ACS Photonics 2017, 4 (3), 476-481. https://doi.org/10.1021/acsphotonics.6b00963.

(4) Dong, Y.; Wang, Y.-K.; Yuan, F.; Johnston, A.; Liu, Y.; Ma, D.; Choi, M.-J.; Chen, B.; Chekini, M.; Baek, S.-W.; Sagar, L. K.; Fan, J.; Hou, Y.; Wu, M.; Lee, S.; Sun, B.; Hoogland, S.; Quintero-Bermudez, R.; Ebe, H.; Todorovic, P.; Dinic, F.; Li, P.; Kung, H. T.; Saidaminov, M. I.; Kumacheva, E.; Spiecker, E.; Liao, L.-S.; Voznyy, O.; Lu, Z.-H.; Sargent, E. H. Bipolar-Shell Resurfacing for Blue LEDs Based on Strongly Confined Perovskite Quantum Dots. Nat. Nanotechnol. 2020, 15 (8), 668-674. https://doi.org/10.1038/s41565-020-0714-5.

(5) Meyns, M.; Perálvarez, M.; Heuer-Jungemann, A.; Hertog, W.; Ibáñez, M.; Nafria, R.; Genç, A.; Arbiol, J.; Kovalenko, M. V.; Carreras, J.; Cabot, A.; Kanaras, A. G. Polymer-Enhanced Stability of Inorganic Perovskite Nanocrystals and Their Application in Color Conversion LEDs. ACS Appl. Mater. Interfaces 2016, 8 (30), 19579 19586. https://doi.org/10.1021/acsami.6b02529.

(6) Zhou, D.; Liu, D.; Pan, G.; Chen, X.; Li, D.; Xu, W.; Bai, $\mathrm{X}$; Song, H. Cerium and Ytterbium Codoped Halide Perovskite Quantum Dots: A Novel and Efficient Downconverter for Improving the Performance of Silicon Solar Cells. Adv. Mater. 2017, 29 (42), 1704149. https://doi.org/10.1002/adma.201704149.

(7) Akkerman, Q. A.; Gandini, M.; Di Stasio, F.; Rastogi, P.; Palazon, F.; Bertoni, G.; Ball, J. M.; Prato, M.; Petrozza, A.; Manna, L. Strongly Emissive Perovskite Nanocrystal Inks for High-Voltage Solar Cells. Nat Energy 2017, 2 (2), 16194. https://doi.org/10.1038/nenergy.2016.194.

(8) Zhang, H.; Wang, X.; Liao, Q.; Xu, Z.; Li, H.; Zheng, L.; $\mathrm{Fu}, \mathrm{H}$. Embedding Perovskite Nanocrystals into a Polymer Matrix for Tunable Luminescence Probes in Cell Imaging.
Adv. Funct. Mater. 2017, 27 (7), 1604382. https://doi.org/10.1002/adfm.201604382.

Wei, Y.; Deng, X.; Xie, Z.; Cai, X.; Liang, S.; Ma, P.; Hou, Z.; Cheng, Z.; Lin, J. Enhancing the Stability of Perovskite Quantum Dots by Encapsulation in Crosslinked Polystyrene Beads via a Swelling-Shrinking Strategy toward Superior Water Resistance. Adv. Funct. Mater. 2017, $\quad 27 \quad$ (39), 1703535. https://doi.org/10.1002/adfm.201703535.

(10) Tamarat, P.; Hou, L.; Trebbia, J.-B.; Swarnkar, A.; Biadala, L.; Louyer, Y.; Bodnarchuk, M. I.; Kovalenko, M. V.; Even, J.; Lounis, B. The Dark Exciton Ground State Promotes Photon-Pair Emission in Individual Perovskite Nanocrystals. Nat Commun 2020, 11 (1), 6001. https://doi.org/10.1038/s41467-020-19740-7.

(11) Pierini, S.; D'Amato, M.; Goyal, M.; Glorieux, Q.; Giacobino, E.; Lhuillier, E.; Couteau, C.; Bramati, A Highly Photostable Perovskite Nanocubes: Toward Integrated Single Photon Sources Based on Tapered Nanofibers. ACS Photonics 2020, 7 (8), 2265-2272. https://doi.org/10.1021/acsphotonics.0c00820.

(12) Zhang, C.; Wang, B.; Li, W.; Huang, S.; Kong, L.; Li, Z.; $\mathrm{Li}, \mathrm{L}$. Conversion of Invisible Metal-Organic Frameworks to Luminescent Perovskite Nanocrystals for Confidential Information Encryption and Decryption. Nat Commun 2017, 8 (1), 1138. https://doi.org/10.1038/s41467-01701248-2

(13) Yakunin, S.; Chaaban, J.; Benin, B. M.; Cherniukh, I.; Bernasconi, C.; Landuyt, A.; Shynkarenko, Y.; Bolat, S.; Hofer, C.; Romanyuk, Y. E.; Cattaneo, S.; Pokutnyi, S. I.; Schaller, R. D.; Bodnarchuk, M. I.; Poulikakos, D.; Kovalenko, M. V. Radiative Lifetime-Encoded Unicolour Security Tags Using Perovskite Nanocrystals. Nat Commun 2021, $12 \quad$ (1), 981. https://doi.org/10.1038/s41467-021-21214-3.

(14) Parobek, D.; Dong, Y.; Qiao, T.; Rossi, D.; Son, D. H. Photoinduced Anion Exchange in Cesium Lead Halide Perovskite Nanocrystals. J. Am. Chem. Soc. 2017, 139 (12), 4358-4361. https://doi.org/10.1021/jacs.7b01480.

(15) Dang, Z.; Shamsi, J.; Palazon, F.; Imran, M.; Akkerman, Q. A.; Park, S.; Bertoni, G.; Prato, M.; Brescia, R.; Manna, L. In Situ Transmission Electron Microscopy Study of Electron Beam-Induced Transformations in Colloidal Cesium Lead Halide Perovskite Nanocrystals. ACS Nano 2017, $\quad 11 \quad$ (2), 2124-2132. https://doi.org/10.1021/acsnano.6b08324.

(16) Huang, H.; Bodnarchuk, M. I.; Kershaw, S. V.; Kovalenko, M. V.; Rogach, A. L. Lead Halide Perovskite Nanocrystals in the Research Spotlight: Stability and Defect Tolerance. ACS Energy Lett. 2017, 2 (9), 2071 2083. https://doi.org/10.1021/acsenergylett.7b00547.

(17) Yang, D.; Li, X.; Zeng, H. Surface Chemistry of All Inorganic Halide Perovskite Nanocrystals: Passivation Mechanism and Stability. Adv. Mater. Interfaces 2018, 5 (8), 1701662. https://doi.org/10.1002/admi.201701662.

(18) Huang, S.; Li, Z.; Wang, B.; Zhu, N.; Zhang, C.; Kong, L.; Zhang, Q.; Shan, A.; Li, L. Morphology Evolution and Degradation of $\mathrm{CsPbBr} 3$ Nanocrystals under Blue LightEmitting Diode Illumination. ACS Appl. Mater. Interfaces $\begin{array}{llll}\text { 2017, } & 9 & \text { (8), } & \text { 7249-7258 }\end{array}$ https://doi.org/10.1021/acsami.6b14423.

(19) Dutta, A.; Behera, R. K.; Dutta, S. K.; Das Adhikari, S.; Pradhan, N. Annealing $\mathrm{CsPbX} 3(\mathrm{X}=\mathrm{Cl}$ and $\mathrm{Br})$ Perovskite Nanocrystals at High Reaction Temperatures: Phase Change and Its Prevention. J. Phys. Chem. Lett. 2018, 9 (22), 6599-6604. https://doi.org/10.1021/acs.jpclett.8b02825. 
(20) Li, F.; Liu, Y.; Wang, H.; Zhan, Q.; Liu, Q.; Xia, Z. Postsynthetic Surface Trap Removal of $\mathrm{CsPbX} 3(\mathrm{X}=\mathrm{Cl}$, $\mathrm{Br}$, or I) Quantum Dots via a ZnX2 /Hexane Solution toward an Enhanced Luminescence Quantum Yield. Chem. Mater. 2018, 30 (23), 8546-8554. https://doi.org/10.1021/acs.chemmater.8b03442.

(21) Bodnarchuk, M. I.; Boehme, S. C.; ten Brinck, S.; Bernasconi, C.; Shynkarenko, Y.; Krieg, F.; Widmer, R.; Aeschlimann, B.; Günther, D.; Kovalenko, M. V.; Infante, I. Rationalizing and Controlling the Surface Structure and Electronic Passivation of Cesium Lead Halide Nanocrystals. ACS Energy Lett. 2019, 4 (1), 63-74. https://doi.org/10.1021/acsenergylett.8b01669.

(22) Krieg, F.; Ong, Q. K.; Burian, M.; Rainò, G.; Naumenko, D.; Amenitsch, H.; Süess, A.; Grotevent, M. J.; Krumeich, F.; Bodnarchuk, M. I.; Shorubalko, I.; Stellacci, F.; Kovalenko, M. V. Stable Ultraconcentrated and Ultradilute Colloids of $\mathrm{CsPbX} 3(\mathrm{X}=\mathrm{Cl}, \mathrm{Br})$ Nanocrystals Using Natural Lecithin as a Capping Ligand. J. Am. Chem. Soc. 2019, $141 \quad$ (50), 19839-19849. https://doi.org/10.1021/jacs.9b09969.

(23) Shi, J.; Ge, W.; Zhu, J.; Saruyama, M.; Teranishi, T. CoreShell $\mathrm{CsPbBr}_{3} @ \mathrm{CdS}$ Quantum Dots with Enhanced Stability and Photoluminescence Quantum Yields for Optoelectronic Devices. ACS Appl. Nano Mater. 2020, 3 (8), 7563-7571. https://doi.org/10.1021/acsanm.0c01204. (24) Ravi, V. K.; Saikia, S.; Yadav, S.; Nawale, V. V.; Nag, A. $\mathrm{CsPbBr} 3 / \mathrm{ZnS}$ Core/Shell Type Nanocrystals for Enhancing Luminescence Lifetime and Water Stability. ACS Energy Lett. 2020, 5 (6), 1794-1796. https://doi.org/10.1021/acsenergylett.0c00858.

(25) Raja, S. N.; Bekenstein, Y.; Koc, M. A.; Fischer, S.; Zhang, D.; Lin, L.; Ritchie, R. O.; Yang, P.; Alivisatos, A. P. Encapsulation of Perovskite Nanocrystals into Macroscale Polymer Matrices: Enhanced Stability and Polarization. ACS Appl. Mater. Interfaces 2016, 8 (51), 35523-35533. https://doi.org/10.1021/acsami.6b09443.

(26) Hai, J.; Li, H.; Zhao, Y.; Chen, F.; Peng, Y.; Wang, B. Designing of Blue, Green, and Red CsPbX3 PerovskiteCodoped Flexible Films with Water Resistant Property and Elimination of Anion-Exchange for Tunable White Light Emission. Chem. Commun. 2017, 53 (39), 54005403. https://doi.org/10.1039/C7CC01152K.

(27) Pan, A.; Wang, J.; Jurow, M. J.; Jia, M.; Liu, Y.; Wu, Y.; Zhang, Y.; He, L.; Liu, Y. General Strategy for the Preparation of Stable Luminous Nanocomposite Inks Using Chemically Addressable CsPbX3 Peroskite Nanocrystals. Chem. Mater. 2018, 30 (8), 2771-2780. https://doi.org/10.1021/acs.chemmater.8b00587.

(28) Xin, Y.; Zhao, H.; Zhang, J. Highly Stable and Luminescent Perovskite-Polymer Composites from a Convenient and Universal Strategy. ACS Appl. Mater. Interfaces 2018, $10 \quad$ (5), 4971-4980. https://doi.org/10.1021/acsami.7b16442.

(29) Lin, C. C.; Jiang, D.-H.; Kuo, C.-C.; Cho, C.-J.; Tsai, Y.H.; Satoh, T.; Su, C. Water-Resistant Efficient Stretchable Perovskite-Embedded Fiber Membranes for LightEmitting Diodes. ACS Appl. Mater. Interfaces 2018, 10 (3), 2210-2215. https://doi.org/10.1021/acsami.7b15989.

(30) Tong, J.; Wu, J.; Shen, W.; Zhang, Y.; Liu, Y.; Zhang, T.; Nie, S.; Deng, Z. Direct Hot-Injection Synthesis of Lead Halide Perovskite Nanocubes in Acrylic Monomers for Ultrastable and Bright Nanocrystal-Polymer Composite Films. ACS Appl. Mater. Interfaces 2019, 11 (9), 93179325. https://doi.org/10.1021/acsami.8b20681.

(31) Papagiorgis, P. G.; Manoli, A.; Alexiou, A.; Karacosta, P.; Karagiorgis, X.; Papaparaskeva, G.; Bernasconi, C.;
Bodnarchuk, M. I.; Kovalenko, M. V.; KrasiaChristoforou, T.; Itskos, G. Robust Hydrophobic and Hydrophilic Polymer Fibers Sensitized by Inorganic and Hybrid Lead Halide Perovskite Nanocrystal Emitters. Front. Chem. 2019, 7, 87. https://doi.org/10.3389/fchem.2019.00087.

Rainò, G.; Landuyt, A.; Krieg, F.; Bernasconi, C.; Ochsenbein, S. T.; Dirin, D. N.; Bodnarchuk, M. I.; Kovalenko, M. V. Underestimated Effect of a Polymer Matrix on the Light Emission of Single $\mathrm{CsPbBr} 3$ Nanocrystals. Nano Lett. 2019, 19 (6), 3648-3653. https://doi.org/10.1021/acs.nanolett.9b00689.

(33) Gandini, M.; Villa, I.; Beretta, M.; Gotti, C.; Imran, M.; Carulli, F.; Fantuzzi, E.; Sassi, M.; Zaffalon, M. Brofferio, C.; Manna, L.; Beverina, L.; Vedda, A.; Fasoli, M.; Gironi, L.; Brovelli, S. Efficient, Fast and Reabsorption-Free Perovskite Nanocrystal-Based Sensitized Plastic Scintillators. Nat. Nanotechnol. 2020, 15 (6), 462-468. https://doi.org/10.1038/s41565-0200683-8.

(34) Lu, Z.; Li, Y.; Qiu, W.; Rogach, A. L.; Nagl, S. Composite Films of $\mathrm{CsPbBr} 3$ Perovskite Nanocrystals in a Hydrophobic Fluoropolymer for Temperature Imaging in Digital Microfluidics. ACS Appl. Mater. Interfaces 2020, 12 (17), 19805-19812. https://doi.org/10.1021/acsami.0c02128.

(35) Huang, S.; Li, Z.; Kong, L.; Zhu, N.; Shan, A.; Li, L. Enhancing the Stability of CH3NH3PbBr3 Quantum Dots by Embedding in Silica Spheres Derived from Tetramethyl Orthosilicate in "Waterless" Toluene. J. Am. Chem. Soc. 2016, 138 (18), 5749-5752. https://doi.org/10.1021/jacs.5b13101.

(36) Li, Z.; Kong, L.; Huang, S.; Li, L. Highly Luminescent and Ultrastable $\mathrm{CsPbBr} 3$ Perovskite Quantum Dots Incorporated into a Silica/Alumina Monolith. Angew. Chem. Int. Ed. 2017, $56 \quad$ (28), 8134-8138. https://doi.org/10.1002/anie.201703264.

(37) Li, S.; Lei, D.; Ren, W.; Guo, X.; Wu, S.; Zhu, Y.; Rogach, A. L.; Chhowalla, M.; Jen, A. K.-Y. Water-Resistant Perovskite Nanodots Enable Robust Two-Photon Lasing in Aqueous Environment. Nat Commun 2020, 11 (1), 1192. https://doi.org/10.1038/s41467-020-15016-2.

(38) Zhang, Q.; Wang, B.; Zheng, W.; Kong, L.; Wan, Q.; Zhang, C.; Li, Z.; Cao, X.; Liu, M.; Li, L. Ceramic-like Stable $\mathrm{CsPbBr} 3$ Nanocrystals Encapsulated in Silica Derived from Molecular Sieve Templates. Nat Commun 2020, 11 (1), 31. https://doi.org/10.1038/s41467-01913881-0.

(39) Dirin, D. N.; Benin, B. M.; Yakunin, S.; Krumeich, F.; Raino, G.; Frison, R.; Kovalenko, M. V. MicrocarrierAssisted Inorganic Shelling of Lead Halide Perovskite Nanocrystals. ACS Nano 2019, 13 (10), 11642-11652. https://doi.org/10.1021/acsnano.9b05481.

(40) Cha, J.-H.; Noh, K.; Yin, W.; Lee, Y.; Park, Y.; Ahn, T. K.; Mayoral, A.; Kim, J.; Jung, D.-Y.; Terasaki, O. Formation and Encapsulation of All-Inorganic Lead Halide Perovskites at Room Temperature in MetalOrganic Frameworks. J. Phys. Chem. Lett. 2019, 10 (9), 2270-2277. https://doi.org/10.1021/acs.jpclett.9b00510.

(41) Huang, H.; Li, J.; Yi, Y.; Wang, J.; Kang, Y.; Chu, P. K.; Ong, H. C.; Yu, X.-F. In Situ Growth of All-Inorganic Perovskite Nanocrystals on Black Phosphorus Nanosheets. Chem. Commun. 2018, 54 (19), 2365-2368. https://doi.org/10.1039/C8CC00029H.

(42) Li, H.; Zheng, X.; Liu, Y.; Zhang, Z.; Jiang, T. Ultrafast Interfacial Energy Transfer and Interlayer Excitons in the Monolayer WS2 /CsPbBr3 Quantum Dot Heterostructure. 
Nanoscale 2018, $10 \quad$ (4), $1650-1659$. https://doi.org/10.1039/C7NR05542K.

(43) Bradley, M.; Bruno, N.; Vincent, B. Distribution of CdSe Quantum Dots within Swollen Polystyrene Microgel Particles Using Confocal Microscopy. Langmuir 2005, 21 (7), 2750-2753. https://doi.org/10.1021/la047322r.

(44) Vaidya, S. V.; Couzis, A.; Maldarelli, C. Reduction in Aggregation and Energy Transfer of Quantum Dots Incorporated in Polystyrene Beads by Kinetic Entrapment Due to Cross-Linking during Polymerization. Langmuir 2015, 31 (10), 3167-3179. https://doi.org/10.1021/la503251s.

(45) O’Brien, P.; Cummins, S. S.; Darcy, D.; Dearden, A.; Masala, O.; Pickett, N. L.; Ryley, S.; Sutherland, A. J. Quantum Dot-Labelled Polymer Beads by Suspension Polymerisation. Chem. Commun. 2003, No. 20, 2532. https://doi.org/10.1039/b307500a.

(46) Koekoekx, R.; Zawacka, N. C.; Van den Mooter, G.; Hens, Z.; Clasen, C. Electrospraying the Triblock Copolymer SEBS: The Effect of Solvent System and the Embedding of Quantum Dots. Macromol. Mater. Eng. 2020, 305 (2), 1900658. https://doi.org/10.1002/mame.201900658.

(47) Lee, S.-K.; Baek, J.; Jensen, K. F. High Throughput Synthesis of Uniform Biocompatible Polymer Beads with High Quantum Dot Loading Using Microfluidic Jet-Mode Breakup. Langmuir 2014, 30 (8), 2216-2222. https://doi.org/10.1021/la4041198.

(48) Percy, S. R. Improvement in Drying and Concentrating of Liquid Substances by Atomizing. US Patent 1872, US125406A, 2.

(49) Sosnik, A.; Seremeta, K. P. Advantages and Challenges of the Spray-Drying Technology for the Production of Pure Drug Particles and Drug-Loaded Polymeric Carriers. Advances in Colloid and Interface Science 2015, 223, 4054. https://doi.org/10.1016/j.cis.2015.05.003.

(50) I Ré, M. MICROENCAPSULATION BY SPRAY DRYING. Drying Technology 1998, 16 (6), 1195-1236. https://doi.org/10.1080/07373939808917460.

(51) Azad, M.; Arteaga, C.; Abdelmalek, B.; Davé, R.; Bilgili, E. Spray Drying of Drug-Swellable Dispersant Suspensions for Preparation of Fast-Dissolving, High Drug-Loaded, Surfactant-Free Nanocomposites. Drug Development and Industrial Pharmacy 2015, 41 (10), $1617-1631$.

https://doi.org/10.3109/03639045.2014.976574.

(52) Sun-Waterhouse, D.; Wadhwa, S. S.; Waterhouse, G. I. N. Spray-Drying Microencapsulation of Polyphenol Bioactives: A Comparative Study Using Different Natural Fibre Polymers as Encapsulants. Food Bioprocess Technol 2013, 6 (9), 2376-2388. https://doi.org/10.1007/s11947012-0946-y

(53) Chu, M.; Zhou, L.; Song, X.; Pan, M.; Zhang, L.; Sun, Y.; Zhu, J.; Ding, Z. Incorporating Quantum Dots into Polymer Microspheres via a Spray-Drying and ThermalDenaturizing Approach. Nanotechnology 2006, 17 (6), 1791-1796. https://doi.org/10.1088/0957-4484/17/6/041.

(54) Li, Y.; Krentz, T. M.; Wang, L.; Benicewicz, B. C.; Schadler, L. S. Ligand Engineering of Polymer Nanocomposites: From the Simple to the Complex. ACS Appl. Mater. Interfaces 2014, 6 (9), 6005-6021. https://doi.org/10.1021/am405332a.

(55) De Roo, J.; Ibáñez, M.; Geiregat, P.; Nedelcu, G.; Walravens, W.; Maes, J.; Martins, J. C.; Van Driessche, I.; Kovalenko, M. V.; Hens, Z. Highly Dynamic Ligand Binding and Light Absorption Coefficient of Cesium Lead Bromide Perovskite Nanocrystals. ACS Nano 2016, 10 (2), 2071-2081. https://doi.org/10.1021/acsnano.5b06295.
Nandiyanto, A. B. D.; Okuyama, K. Progress in Developing Spray-Drying Methods for the Production of Controlled Morphology Particles: From the Nanometer to Submicrometer Size Ranges. Advanced Powder Technology 2011, 22 (1), 1-19. https://doi.org/10.1016/j.apt.2010.09.011.

(57) Boel, E.; Koekoekx, R.; Dedroog, S.; Babkin, I.; Vetrano, M. R.; Clasen, C.; Van den Mooter, G. Unraveling Particle Formation: From Single Droplet Drying to Spray Drying and Electrospraying. Pharmaceutics 2020, 12 (7), 625. https://doi.org/10.3390/pharmaceutics12070625.

(58) Bögelein, J.; Lee, G. Cyclone Selection Influences Protein Damage during Drying in a Mini Spray-Dryer. International Journal of Pharmaceutics 2010, 401 (1-2), 68-71. https://doi.org/10.1016/j.ijpharm.2010.09.023.

(59) Beck-Broichsitter, M.; Strehlow, B.; Kissel, T. Direct Fractionation of Spray-Dried Polymeric Microparticles by Inertial Impaction. Powder Technology 2015, 286, 311317. https://doi.org/10.1016/j.powtec.2015.08.033.

(60) Baranov, D.; Toso, S.; Imran, M.; Manna, L. Investigation into the Photoluminescence Red Shift in Cesium Lead Bromide Nanocrystal Superlattices. J. Phys. Chem. Lett. 2019, $10 \quad$ (3), 655-660 https://doi.org/10.1021/acs.jpclett.9b00178.

(61) de Quilettes, D. W.; Vorpahl, S. M.; Stranks, S. D.; Nagaoka, H.; Eperon, G. E.; Ziffer, M. E.; Snaith, H. J.; Ginger, D. S. Impact of Microstructure on Local Carrier Lifetime in Perovskite Solar Cells. Science 2015, 348 (6235),

https://doi.org/10.1126/science.aaa5333.

(62) Cottingham, P.; Brutchey, R. L. On the Crystal Structure of Colloidally Prepared CsPbBr3 Quantum Dots. Chem. Commun. 2016, 52 (30), 5246-5249. https://doi.org/10.1039/C6CC01088A.

(63) Bertolotti, F.; Protesescu, L.; Kovalenko, M. V.; Yakunin, S.; Cervellino, A.; Billinge, S. J. L.; Terban, M. W.; Pedersen, J. S.; Masciocchi, N.; Guagliardi, A. Coherent Nanotwins and Dynamic Disorder in Cesium Lead Halide Perovskite Nanocrystals. ACS Nano 2017, 11 (4), 38193831. https://doi.org/10.1021/acsnano.7b00017.

(64) Galisteo-López, J. F.; Anaya, M.; Calvo, M. E.; Míguez, H. Environmental Effects on the Photophysics of OrganicInorganic Halide Perovskites. J. Phys. Chem. Lett. 2015, 6 (12),

https://doi.org/10.1021/acs.jpclett.5b00785.

(65) Motti, S. G.; Gandini, M.; Barker, A. J.; Ball, J. M.; Srimath Kandada, A. R.; Petrozza, A. Photoinduced Emissive Trap States in Lead Halide Perovskite Semiconductors. ACS Energy Lett. 2016, 1 (4), 726-730. https://doi.org/10.1021/acsenergylett.6b00355.

(66) Lorenzon, M.; Sortino, L.; Akkerman, Q.; Accornero, S.; Pedrini, J.; Prato, M.; Pinchetti, V.; Meinardi, F.; Manna, L.; Brovelli, S. Role of Nonradiative Defects and Environmental Oxygen on Exciton Recombination Processes in $\mathrm{Cs} \mathrm{PbBr} 3$ Perovskite Nanocrystals. Nano Lett. 2017, $\quad 17 \quad$ (6), 3844-3853. https://doi.org/10.1021/acs.nanolett.7b01253.

(67) Carrillo-Carrión, C.; Cárdenas, S.; Simonet, B. M.; Valcárcel, M. Quantum Dots Luminescence Enhancement Due to Illumination with UV/Vis Light. Chem. Commun. 2009, No. 35, 5214. https://doi.org/10.1039/b904381k.

(68) Javaux, C.; Mahler, B.; Dubertret, B.; Shabaev, A.; Rodina, A. V.; Efros, Al. L.; Yakovlev, D. R.; Liu, F.; Bayer, M.; Camps, G.; Biadala, L.; Buil, S.; Quelin, X.; Hermier, J.-P. Thermal Activation of Non-Radiative Auger Recombination in Charged Colloidal Nanocrystals. 
Nature Nanotech 2013, 8 (3), 206-212. https://doi.org/10.1038/nnano.2012.260.

(69) Huang, S.-C.; Yeh, C.-W.; Chen, G.-H.; Liu, M.-C.; Chen, H.-S. Investigation of Luminescence Enhancement and Decay of QD-LEDs: Interface Reactions between QDs and Atmospheres. ACS Appl. Mater. Interfaces 2019, 11 (2), 2516-2525. https://doi.org/10.1021/acsami.8b18558.

(70) Xie, B.; Hu, R.; Luo, X. Quantum Dots-Converted LightEmitting Diodes Packaging for Lighting and Display:
Status and Perspectives. Journal of Electronic Packaging 2016, 138 (2), 020803. https://doi.org/10.1115/1.4033143.

(71) Coe-Sullivan, S.; Liu, W.; Allen, P.; Steckel, J. S. Quantum Dots for LED Downconversion in Display Applications. ECS J. Solid State Sci. Technol. 2013, 2 (2), R3026-R3030. https://doi.org/10.1149/2.012302jss.

Table of Contents (TOC)

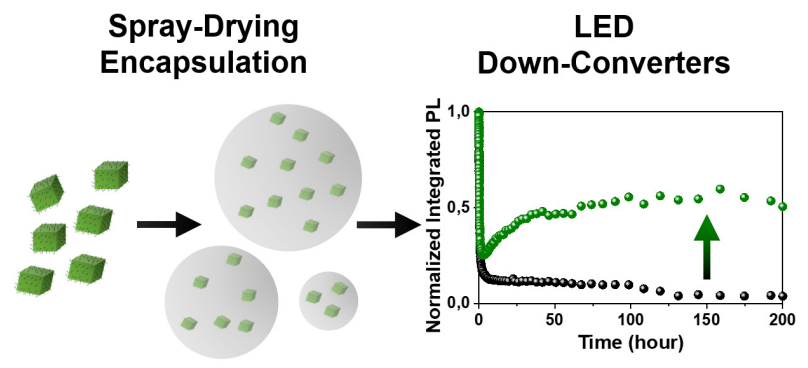

NCs/Polymeric Beads

Enhanced Photo-stability 